\title{
ANALISIS PERAN PEREMPUAN DALAM RANTAI NILAI IKAN KALENG PRODUK TUNA CAKALANG DI PT. DELTA PASIFIC INDOTUNA DI KOTA BITUNG PROVINSI SULAWESI UTARA

\author{
Irna S. Jumadi'; Jeannette F. Pangemanan²; Grace O. Tambani²
} \\ 1) Mahasiswa Fakultas Perikanan dan IImu Kelautan Universitas Sam Ratulangi, Manado. \\ 2) Staff Pengajar Fakultas Perikanan dan IImu Kelautan Universitas Sam Ratulangi, Manado. Koresponden email: franskarangan@ymail.com
}

\begin{abstract}
Women are a resource that is no less important than the male workforce. Women contribute significantly to the economic survival and well-being of households and communities. One of the areas of fisheries development, in the city of Bitung has many fishing company engaged in canning. Labor in the city of Bitung canning company includes not only men only, but women as well. The woman is actually an economic resource that is no less important than men. Presence of women in the household not just as a complement to the reproductive function, but more than that of women proved to contribute significantly to the economic viability and prosperity of the household and the community. This study uses a base case study survey approach, which is done by simple random sampling and the population is female employee at PT. Delta Pacific Indotuna. Data collected in the form of primary data that data collected through interviews using questionnaires as well as observers direct and secondary data obtained from agencies that may be able to provide data for this study include: the Department of Fisheries of North Sulawesi, the Fisheries Department Bitung and the results of searching the internet. The data analysis used is qualitative analysis and quantitative analysis. The results of research related to women's role in the value chain canned fish in PT. Delta Pacific Indotuna provide information that women are the greatest role in the activities of Beheading, Skinning and Loinning. The third reason is because this activity is highly demanded high precision that is difficult to do by men. The role of women at least contained in the cooling activity, this activity is considered difficult to be done by women because of the risk of his job is quite high.
\end{abstract}

Keywords: analysis, role, women, product

\begin{abstract}
Abstrak
Perempuan merupakan sumber daya yang tidak kalah pentingnya dengan tenaga kerja pria. Perempuan memberikan sumbangan yang besar bagi kelangsungan perekonomian dan kesejahteraan rumah tangga serta masyarakat. Salah satu kawasan pengembangan perikanan, di kota Bitung memiliki banyak perusahaan perikanan yang bergerak dibidang pengalengan ikan. Tenaga kerja dalam perusahaan pengalengan kota Bitung tidak hanya mencakup kaum pria saja, akan tetapi kaum perempuan juga. Perempuan sesungguhnya merupakan sumber daya ekonomi yang tidak kalah pentingnya dibandingkan dengan pria. Keberadaan perempuan dalam rumah tangga bukan sekedar sebagai pelengkap fungsi reproduksi saja, namun lebih dari itu perempuan terbukti memberikan sumbangan yang besar bagi kelangsungan ekonomi dan kesejateraan rumah tangga serta masyarakat. Penelitian ini menggunakan dasar penelitian studi kasus dengan pendekatan survey, yang dilakukan dengan cara sampling acak sederhana dan yang menjadi populasi yaitu karyawan perempuan yang ada di PT. Delta Pasific Indotuna. Data yang dikumpulkan berupa data primer yaitu data yang dikumpulkan melalui wawancara dengan menggunakan kuisioner serta pengamat langsung dan data sekunder yang diperoleh dari instansi-instansi yang dapat dapat menyediakan data untuk penelitian ini antara lain : Dinas Perikanan Sulawesi Utara, Dinas Perikanan kota Bitung serta hasil dari searching internet. Analisis data yang digunakan yaitu analisis kualitatif dan analisis kuantitatif. Hasil penelitian terkait peranan perempuan dalam rantai nilai ikan kaleng di PT. Delta Pasific Indotuna memberikan informasi bahwa peranan terbesar perempuan terdapat pada kegiatan Beheading, Skinning dan Loinning. Alasannya karena pada ketiga kegiatan ini sangat dituntut ketelitian tinggi yang sulit untuk dilakukan oleh laki-laki. Peran perempuan yang paling sedikit terdapat pada kegiatan cooling, kegiatan ini dinilai sulit untuk dilakukan oleh perempuan karena resiko dari pekerjaanya yang cukup tinggi.
\end{abstract}

Kata kunci: analisis, peran, perempuan, produk 



\section{PENDAHULUAN}

Wilayah perairan Provinsi

Sulawesi Utara merupakan tempat yang sangat potensial dan ideal bagi pengembangan sektor perikanan. Perairan Provinsi Sulawesi Utara didalamnya terkandung sumberdaya alam hayati dan non hayati. Sumberdaya hayati yang terdapat dalam laut Sulawesi Utara terdiri dari berbagai jenis ikan, crustacea, mollusca, rumput laut/alga, padang lamun, mangrove, dan terumbu karang (Kementrian Kelautan Perikanan, 2013).

Rantai nilai merupakan salah satu aspek tepenting dalam produk perikanan. Menurut Raras (2009), rantai nilai merupakan aktifitas yang berawal dari bahan mentah sampai dengan penanganan purna jual yang melibatkan pelaku usaha terkait pada setiap mata rantai dalam pemasaran produknya.

Perkembangan usaha perikanan di Sulawesi Utara mengacu pada pembangunan sektor perikanan dan kelautan nasional. Melihat dari potensi sumberdaya alam, sektor perikanan dan kelautan menjadi salah satu program unggulan pembangunan ekonomi Sulawesi Utara. Dengan mengetahui potensi sumberdaya yang besar dan usaha penangkapan, budidaya dan usaha pengelolaan usaha hasil perikanan maka pemerintah menetapkan subsektor perikanan sebagai salah satu motor penggerak pembangunan.

Kota Bitung merupakan salah satu kawasan pengembangan perikanan di Provinsi Sulawesi Utara. Bitung memiliki infrastruktur yang mendukung bongkar muat barang dari dan ke kota Bitung dan Pelabuhan Perikanan Samudra (PPS) Bitung. Peran infrastruktur tersebut sangat mendukung kawasan industri perikanan Bitung sebagai penghasil produk perikanan untuk pasar domestik dan manca Negara (Dinas Pertanian dan Perikanan Provinsi Sulawesi Utara, 2009).

Menurut Rahma dalam Suyanto \& Hendrarso (1996) mengatakan bahwa perempuan sesungguhnya merupakan sumber daya ekonomi yang tidak kalah pentingnya dibandingkan dengan pria. Keberadaan perempuan dalam rumah tangga bukan sekedar sebagai pelengkap fungsi reproduksi saja, namun lebih dari itu perempuan terbukti memberikan sumbangan yang besar bagi kelangsungan ekonomi dan kesejateraan rumah tangga serta masyarakat.

Salah satu kawasan pengembangan perikanan, kota Bitung memiliki banyak perusahaan perikanan yang bergerak dibidang pengalengan ikan. Tenaga kerja dalam perusahaan pengalengan kota Bitung tidak hanya mencakup kaum pria saja, akan tetapi kaum perempuan juga. Banyaknya tenaga kerja perempuan akan banyak memberikan partisipasi dalam produksi perikanan, hal inilah yang menjadikan penulis tertarik untuk melaksanakan penelitian pada tenaga kerja perempuan di kota Bitung. 


\section{Tujuan dan Manfaat Penelitian}

Tujuan dari Penelitian ini adalah : (1) Mengidentifikasi peran perempuan dalam rantai nilai produk pengalengan Tuna-Cakalang di PT. Delta Pasific Indotuna. (2) Melihat peranan perempuan dalam rantai nilai produk pengalengan Tuna-Cakalang di PT. Delta Pasific Indotuna.

Adapun manfaat dari Penelitian ini adalah sebagai berikut :

1) Untuk mendapatkan gelar sarjana bagi penulis pada Fakultas Perikanan dan IImu Kelautan Universitas Sam Ratulangi;

2) Untuk bahan masukan bagi pemerintah setempat di kota Bitung dalam menyusun kebijakan dalam sektor kelautan dan perikanan.

\section{METODE PENELITIAN}

Penelitian ini bersifat deskriptif, yaitu dengan membuat penggambaran secara sistematis, faktual, dan akurat mengenai faktor-faktor dan sifat-sifat populasi di daerah tertentu (Hamidi, 2010). Penelitian deskriptif adalah penelitian yang bertujuan mengungkapkan suatu kenyataan sosial dengan jalan mendeskripsikan secara tepat sifat-sifat individu, keadaan, gejala, kelompok tertentu berkenaan dengan masalah unit yang diteliti dalam masyarakat (Faisal, 2003). Menurut Nazir (2009), metode penelitian desktriptif merupakan metode penelitian yang menggambarkan dan menginterpretasikan objek sesuai apa adanya. Metode deskriptif adalah suatu metode dalam meneliti status kelompok manusia, suatu objek, suatu set kondisi, suatu sistem pemikiran ataupun suatu kelas peristiwa pada masa sekarang. Tujuan dari penelitian deskriptif ini adalah untuk membuat deskripsi, gambaran atau lukisan secara sistematis, factual dan akurat mengenai fakta-fakta, sifat-sifat serta hubungan antara fenomena yang diselidiki.

Penelitian ini menggunakan dasar penelitian studi kasus. Mantjoro dkk (1989), menyatakan bahwa studi kasus adalah penelitian yang dilakukan dengan cara mempelajari satu kasus tertentu dan pada objek yang terbatas. Sedangkan menurut bungin (2003), penelitian studi kasus adalah studi yang bersifat komprehensif intens, dan mendalam serta lebih diarahkan pada upaya menelaah masalah-masalah atau fenomena yang bersifat kontemporer. Ditinjau dari wilayahnya maka penelitian kasus ini hanya meliputi daerah atau subjek yang sangat sempit, tetapi ditinjau dari sifat penelitian, penelitian kasus lebih mendalam.

Penelitian dengan bentuk dasar studi kasus ini bersifat deskriptif yaitu menggambarkan atau menguraikan peristiwa-peristiwa secara umum sehubungan dengan objek penelitian. Hasil penelitian studi kasus pada satu perusahaan tidak dapat diberlakukan pada studi kasus yang sama pada perusahaan yang lain meskipun masih dalam wilayan yang berdekatan.

Data penelitian ini berasal dari dua sumber yaitu data primer dan data 
sekunder. Data primer dikumpulkan melalui pengamatan langsung dan wawancara langsung terhadap setiap responden. Pengumpulan data dilaksanakan dengan sikap yang komunikatif serta mengajukan beberapa pertanyaan menggunakan bahasa Indonesia yang mudah dipahami dalam bentuk kuesioner yang sudah disiapkan secara sistematis. Data sekunder diperoleh dari instansi-instansi yang dapat dapat menyediakan data untuk penelitian ini antara lain : Dinas Perikanan Sulawesi Utara, Dinas Perikanan kota Bitung serta hasil dari searching internet.

\section{HASIL DAN PEMBAHASAN}

Keadaan Lokasi PT. Delta Pasific Indotuna

PT. Delta Pasific Indotuna ini mempunyai lokasi yang sangat strategis dimana lokasinya disamping laut serta di dekat jalan raya, PT. Delta Pasific Indotuna yang terletak di jalan Veteran lingkungan IV Kelurahan Girian Bawah Kecamatan Girian Bitung 95542. Lokasi perusahaan $\pm 250 \mathrm{~m}$ dari jalan raya dengan fasilitas jalan di paving, kondisi yang demikian tersebut dapat menunjang kebersihan dan proses produksi khususnya transportasi dalam mendatangkan bahan baku dan mengirim hasil produk.

\section{Sejarah PT. Delta Pasific Indotuna}

PT. Delta Pasific Indotuna adalah perusahaan yang dirikan atas izin investasi yang diterbitkan oleh Badan
Koordinasi Penanaman Modal (BKPM) No.178/PMDN/2005 pada tanggal 15 Desember 2005. PT. Delta Pasific Indotuna adalah perusahaan modalnya tergolong sebagai Penanaman Modal Dalam Negeri ( PMDM ), dimana pemilik modal atau sahamnya adalah warga Negara Indonesia yang berdomisili di Surabaya, Jawa Timur. Persetujuan penanaman modal sudah mengalami perubahan satu kali mengenai bidang usaha yaitu penambahan industry pengolahan wadah dari logam (yang sudah diusulkan sejak dari awal) yang di tuangkan dalam surat persetujuan perubahan

PMDN

No.76/111/PMDM/2006 tertanggal 23 Juli 2006. Pembangunan pabrik PT. Delta Pasific Indotuna, dimulai sejak pertengahan akhir Januari 2006, yaitu sejak diperolehnya Izin Mendirikan Bangunan (IMB) dari dinas kota, kota Bitung atas nama Walikota Bitung NO.II/IIB tahun 2006 pada tanggal 24 Januari 2006. IMB tersebut diperoleh setelah PT. Delta Pasific Indotuna sebelumnya mendapatkan persetujuan dari masyarakat sekitar lokasi pendirian pabrik yang di ketahui oleh Lurah Girian Bawah yang disertai oleh Camat Bitung Barat, PT. Delta Pasific Indotuna juga memiliki izin UU gangguan/HO NO.503.1/EKON/II/02, dan diterbitkan oleh Sekretariat Daerah Kota Bitung atas nama Walikota Bitung. Pembangunan pabrik dengan segala fasilitasnya membutuhkan waktu sekitar sebelas bulan, sehingga pada awal Desember 2006 trial production ( uji coba produksi 
sudah mulai dilakukan ). Komersial production di mulai sejak Januari 2007 4PCL. Fullcontainer looded (4 kali 1700 karton 48 kaleng perkarton atau sama dengan 4 kali 81.600 pcs kaleng dengan ukuran berat bersih/Net weight 185 gram) dengan Negara tujuan ekspor Damman, Jeddah, Saudi Arabia. Sejak didirikan perusahaan tersebut telah memiliki 4 unit produksi ( plant) yaitu : unit pengalengan ikan (cannery ) kapasitas $50 \mathrm{~kg}$ bahan baku ikan/hari pabrik teoung ikang ( rendering plant).

Ikan kaleng yang dihasilkan dibedakan atas jenis Cakalang ( Skipjack ), dan Tuna ( Yellowfin ) dengan menggunakan kemasan kaleng yang berukuran 307x111, vegetable oil/minyak kedelai, minyak biji bunga matahari atau minyak kanola serta model pengepakannya berbentuk (sopllidd, chunk dan flakes). Frozen precooked tuna loins di kemas dengan vacuum pack dengan berat $5 \mathrm{~kg} /$ pack. Tepung ikan yang merupakan produk sampingan sebagai hasil dari pengolahan limbah pengalengan dipasarkan di dalam negeri, es balok yang diproduksi di samping untuk di pakai sendiri, juga dijual kepada kapal ikan-ikan dan perusahaan lainnya, sedangkan kaleng di produksi hanya untuk di gunakan sendiri. Pangsa pasar utama ikan kaleng adalah Negara-negara di timur tengah (middle east) seperti Saudi Arabia ( KSA ), Republic of Yemen (Yaman), Yordania, Syria, Kuwait, dan lain-lain. Sedangkan Frozen Precooked Tuna loins ke Yaman dan Meksiko. Untuk dipasarkan ke Afrika Serikat dan Eropa, masih dalam tahap pengurusan perizinan. Meskipun per tanggal 30 Mei 2007 PT. Delta Pasific Indotuna mendapatkan sertifikat registrasi dari USA-FDA (United State of Amerika food and Drug Administration) dengan no.15099 PT. Delta Pasific Indotuna di resmikan oleh menteri perdagangan dan perindustrian lbu Maria Elka Pangestu pada tanggal 31 Desember 2007.

\section{Keadaan PT. Delta Pasific Indotuna Menurut Jumlah Karyawan}

Jumlah karyawan yang bekerja pada PT. Delta Pasific Indotuna adalah 1124 orang dengan komposisi laki-laki sebayak 225 orang dan perempuan sebanyak 899 orang. Jumlah karyawan yang ada dapat dilihat pada tabel di bawah ini.

Tabel. Keadaan PT. Delta Pasific Indotuna Menurut Jumlah Karyawan

\begin{tabular}{|c|c|c|c|}
\hline No & Jenis Kelamin & Jumlah & Persentase (\%) \\
\hline 1 & Laki-laki & 225 & 20 \\
\hline 2 & Perempuan & 899 & 80 \\
\hline & & 1124 & 100 \\
\hline
\end{tabular}

Sumber : Data Sekunder Diolah 2017

Berdasarkan tabel di atas menggambarkan bahwa jumlah karyawan perempuan sebanyak 899 orang (sebesar $80 \%$ ) jauh lebih banyak dibandingkan dengan karyawan laki-laki yang hanya berjumlah 225 orang (sebesar 20\%). Banyaknya karyawan perempuan di karenakan dalam kegiatan produksi di PT. Delta Pasific Indotuna ketelitian adalah hal yang diutamakan 
dan biasanya perempuan lebih teliti dibandingkan dengan laki-laki.

Peran karyawan laki-laki di PT. Delta Pasific Indotuna adalah sebagai pengangkut bahan baku dari satu bagian ke bagian lainnya. Hal ini dikarenakan berat bahan baku yang dapat mencapai $60 \mathrm{~kg}$, sehingga tidak memungkinkan di angkut oleh karyawan perempuan. Sedangkan karyawan perempuan di tempatkan di bagian produksi karena ketelitian, keterampilan dan kecepatan kerja merupakan hal yang sangat penting dalam bidang produksi.

\section{Keadaan Karyawan Keadaan Umum} PT. Delta Pasific Indotuna Menurut Umur

Salah satu variabel yang sangat berpengaruh dalam banyaknya produksi karyawan adalah umur karyawan. Seperti yang tergambar pada tabel 0.2.

Tabel. Keadaan PT. Delta Pasific Indotuna Menurut Umur

\begin{tabular}{|c|c|c|c|}
\hline No & Umur & Jumlah (Perempuan) & Persentase \\
\hline 1 & $15-25$ & 12 & $13 \%$ \\
\hline 2 & $26-35$ & 33 & $37 \%$ \\
\hline 3 & $36-45$ & 35 & $39 \%$ \\
\hline 4 & $46-55$ & 9 & $10 \%$ \\
\hline \multicolumn{2}{|c|}{ Jumlah } & 89 & $100 \%$ \\
\hline
\end{tabular}

Sumber : Data Primer diolah 2017

Pada tabel yang telah disajikan dapat dilihat bahwa sebagian besar karyawan perempuan di PT. Delta Pasific Indotuna berada pada umur produktif yaitu umur 26-35 dan 36-45. Umur tenaga kerja terbanyak adalah 3645 tahun dengan persentase 39\%, sedangkan umur tenaga kerja yang paling sedikit adalah 46-55 tahun dengan persentase 10\%. Dapat di simpulkan bahwa karyawan yang bekerja di PT. Delta Pasific Indotuna jika dilihat dari umur sangat produktif.

Walaupun

perusahaan mempekerjakan tenaga kerja dengan umur 46-55 tahun, namun perusahaan mempunyai pertimbangan khusus mungkin tenaga kerja tersebut memiliki keterampilan khusus yang dibutuhkan perusahaan.

\section{Keadaan Karyawan PT. Delta Pasifik Indotuna Menurut Suku}

Keadaan karyawan di PT. Delta Pasifik Indotuna tidak lepas dari suku yang berbeda-beda. Sebarannya dapat dilihat pada tebel 0.3 di bawah ini.

Tabel. Keadaan Karyawan PT. Delta Pasific Indotuna Menurut suku

\begin{tabular}{|c|l|c|c|}
\hline No & \multicolumn{1}{|c|}{ Suku } & Jumlah & Persentase \\
\hline 1 & Bugis/Buton & 6 & $7 \%$ \\
\hline 2 & Gorontalo & 35 & $39 \%$ \\
\hline 3 & Minahasa & 9 & $10 \%$ \\
\hline 4 & Mongondouw & 13 & $15 \%$ \\
\hline 6 & Sangihe & 24 & $27 \%$ \\
\hline 8 & Toraja & 2 & $2 \%$ \\
\hline & Jumlah & 89 & $100 \%$ \\
\hline
\end{tabular}

Sumber : Data Primer diolah 2017

Data yang ada menunjukan bahwa 35 orang karyawan di PT. Delta Pasifik Indotuna 39\% berasal dari suku Gorontalo dan yang paling rendah adalah Toraja yaitu sebesar $2 \%$. Hal ini menunjukan bahwa PT. Delta Pasifik Indotuna menyerap tenaga kerja bukan hanya berasal dari suku tertentu saja 
tetapi setiap pekerja dari suku-suku yang lainpun akan diterima sesuai keterampilan yang mereka miliki. Penduduk yang datang dan tinggal di sekitar perusahaan yang paling dominan adalah Gorontalo.

\section{Keadaan Karyawan PT. Delta Pasifik Indotuna Menurut Tingkat Pendidikan}

Varibel pendidikan juga diungkapkan dalam penelitian ini dan hasilnya dapat dilihat pada tabel di bawah ini.

Tabel. Keadaan Karyawan PT. Delta Pasific Indotuna Menurut Tingkat Pendidikan

\begin{tabular}{|c|c|c|c|}
\hline No & Pendidikan & Jumlah & Persentase \\
\hline 1 & SD & 3 & $3,37 \%$ \\
\hline 2 & SMP & 16 & $17,98 \%$ \\
\hline 3 & SMA & 68 & $76,40 \%$ \\
\hline 4 & D3 & 1 & $1,12 \%$ \\
\hline 5 & S1 & 1 & $1,12 \%$ \\
\hline \multicolumn{2}{|c|}{ Jumlah } & 89 & $100 \%$ \\
\hline
\end{tabular}

Sumber : Data Primer diolah 2017

Tingkat pendidikan sangat menentukan kualitas dan kemampuan tenaga kerja. Pendidikan secara aktif dapat mengembangkan potensi kerja untuk memilki kekuatan spiritual, keagamaan, pengendalian diri, kepribadian, kecerdasan, ahlak mulia serta keterampilan yang diperlukan untuk memanfaatkan segala fasilitas yang ada dilingkungan perusahaan dengan tujuan meningkatkan produktivitas kerja. Produktivitas kerja sesorang dapat dipengaruhi oleh motivasi dari setiap tenaga kerja dan tingkat pendidikan yang sudah diterima.
Berdasarkan data tabel yang dapat dilihat bahwa sebagian besar tenaga kerja di PT. Delta Pasifik Indotuna memiliki latar belakang pendidikan SMA yaitu $76,40 \%$ sebanyak 68 orang dan yang paling sedikit adalah karyawan yang memiliki latar belakang pendidikan D3 dan S1 yaitu 1,12\% masing-masing sebanyak 1 orang.

\section{Keadaan Karyawan PT. Delta Pasific Indotuna Menurut Tanggungan Keluarga}

Dari penelitian yang dilakukan maka diperoleh data jumlah tanggungan keluarga karyawan PT. Delta Pasifik Indotuna seperti pada tabel 0.5 berikut.

Tabel. Keadaan Karyawan PT. Delta Pasific Indotuna Menurut Tanggungan Keluarga

\begin{tabular}{|c|l|c|c|}
\hline No & $\begin{array}{c}\text { Jumlah tanggungan } \\
\text { keluarga }\end{array}$ & Jumlah & $\%$ \\
\hline 1 & Tidak ada & 5 & $6 \%$ \\
\hline 2 & $1-2$ & 74 & $83 \%$ \\
\hline 3 & $3-5$ & 10 & $11 \%$ \\
\hline \multicolumn{2}{|c|}{ Jumlah } & 89 & $100 \%$ \\
\hline
\end{tabular}

Sumber : Data Primer diolah 2017

Tabel di atas menunjukan jumlah tanggungan keluarga karyawan. Dari 89 responden sebagain besar memiliki 1-2 tanggungan keluarga yaitu $83 \%$ kemudian karyawan yang memiliki 3-5 tanggungan keluarga hanya sebesar $11 \%$. Adapun karyawan yang tidak memiliki tanggungan keluarga karena belum menikah. 


\section{Profil Aktivitas}

Profil aktivitas menggambarkan pembagian kerja laki-laki dan perempuan dalam kegiatan produktif, reproduktif dan sosial. Kegiatan produktif meliputi Fish Receiving (Penerimaan Ikan), Thawing (Pelelehan Ikan), Butchering (Penyiangan/Pembersihan Isi Perut), Pencucian, pre-cooking (Pemasakan awal), Colling (Pendinginan), Beheading, Skinning, Loinning (Pemotongan Kepala, kulit, pengeluaran tulang), Pencucian Kaleng Kosong, Packing (Pengisian Daging Ikan), penimbangan, Filling Medium (Pengisian medium), Seaming (penutupan kaleng), can washing (pencucian kaleng), Sterilisasi/retorting, Pendinginan Kaleng, Case Up (Pengartonan), Pelabelan, Penyimpanan, dan Pemasaran.

Tabel. Keadaan Karyawan PT. Delta Pasific Indotuna Menurut Kegiatan Produktif

\begin{tabular}{|c|l|c|c|}
\hline \multirow{2}{*}{ No } & \multirow{2}{*}{ Kegiatan } & \multicolumn{2}{c|}{$\begin{array}{c}\text { Partisipasi } \\
\text { Perempuan }\end{array}$} \\
\cline { 3 - 4 } & & Ada & Tidak Ada \\
\hline 1 & Fish Receiving & - & $\sqrt{ }$ \\
\hline 2 & Thawing & - & $\sqrt{ }$ \\
\hline 3 & Butchering & - & $\sqrt{ }$ \\
\hline 4 & Pencucian & - & $\sqrt{ }$ \\
\hline 5 & Pemasakan awal & $\sqrt{ }$ & - \\
\hline 6 & Colling & $\sqrt{ }$ & - \\
\hline 7 & Beheading & $\sqrt{ }$ & - \\
\hline 8 & Skinning & $\sqrt{ }$ & - \\
\hline 9 & Loinning & $\sqrt{ }$ & - \\
\hline 10 & Pencucian Kaleng & $\sqrt{ }$ & - \\
\hline 11 & Kosong & $\sqrt{ }$ & - \\
\hline 12 & Penimbangan & $\sqrt{ }$ & - \\
\hline 13 & Filling Medium & $\sqrt{ }$ & - \\
\hline 14 & Seaming & $\sqrt{ }$ & - \\
\hline
\end{tabular}

\begin{tabular}{|c|l|c|c|}
\hline 15 & can washing & $\sqrt{ }$ & - \\
\hline 16 & Sterilisasi/retorting & - & $\sqrt{ }$ \\
\hline 17 & Pendinginan Kaleng & $\sqrt{ }$ & - \\
\hline 18 & Pengartonan & - & $\sqrt{ }$ \\
\hline 19 & Pelabelan & $\sqrt{ }$ & - \\
\hline 20 & Penyimpanan & - & $\sqrt{ }$ \\
\hline 21 & Pemasaran & - & $\sqrt{ }$ \\
\hline \multicolumn{2}{|l|}{ Jumlah } & 13 & 8 \\
\hline \multicolumn{2}{|l|}{ Persentase (\%) } & $62 \%$ & $38 \%$ \\
\hline
\end{tabular}

Sumber : Data Primer diolah 2017

Penggunaan tenaga kerja/tenaga bantu dalam kegiatan produktif yaitu mulai dari Fish Receiving di kapal sampai pada pemasaran, dapat dilihat bahwa keterlibatan perempuan cukup banyak yaitu $62 \%$ sedangkan keterlibatan laki-laki sebanyak $38 \%$. Perlu diketahui bahwa kegiatan meliputi Fish Receiving, Thawing, Butchering, Pencucian ikan memerlukan tenaga yang kuat oleh karena itu dalam kegiatan pada tabel 0.6 terlihat bahwa kegiatan tersebut dominan dilakukan oleh lakilaki.

Kegiatan reproduktif meliputi: pembersihan alat (sanitasi), teknisi, satpam, supir, operator, administrasi (pencatatan), dan quality control. Perempuan di PT. Delta Pasifik Indotuna tidak banyak ikut campur dalam kegiatan reproduktif, hal ini di karenakan beban tugas dan skill yang sangat jarang dimiliki perempuan. Contoh Kegiatan reproduktif yang tidak mungkin di lakukan oleh perempuan yaitu pembersihan alat, teknisi, satpam, supir, karena beban, skill, dan resikonya terlalu besar untuk perempuan. Sementara itu untuk kegiatan operator, administrasi 
(pencatatan), dan quality control masih dapat dilakukan oleh perempuan karena beban dan resiko kegiatannya masih bisa ditanggung oleh perempuan.

Berbeda dengan dua jenis kegiatan sebelumnya yang didominasi oleh salah satu pihak, kegiatan sosial lebih banyak dilakukan bersama. Kegiatan sosial karyawan di PT. Delta Pasifik Indotuna meliputi keagamaan, PKK, HUT, perkawinan, kedukaan, kerja bhakti. Satu kegiatan sosial di PT. Delta Pasifik Indotuna adalah kegiatan keagamaan yang rutin dilakukan setiap minggu. Sementara itu untuk kegiatan arisan lebih lebih banyak di laksanakan oleh perempuan, laki-laki akan datang ketika istrinya tidak bisa hadir, itupun hanya sekedar mengantarkan uang.

Hasil penelitian ternyata pekerjapekerja yang ada di PT. Delta Pasifik Indotuna tergabung dan mengikuti kegiatan-kegiatan organisasi sosial yang ada di sekitar tempat tinggal mereka. Kegiatan ini terdiri dari organisasi sosial ibu-ibu PKK, dan kelompok keagamaan seperti pengajian dan tadzkir bagi agama Islam dan untuk agama Kristen seperti kaum bapa, kaum ibu, remaja dan pemuda Kristen. Setiap organisasi ini melibatkan karyawan yang bekerja di PT. Delta Pasifik Indotuna.

Organisasi PKK secara rutin dilaksanakan setiap minggu, didalam kegiatan tersebut yang diikuti adalah arisan uang. Ibu-ibu mengikuti kegiatan PKK selain sebagai sarana melatih diri agar supaya tidak tersisih dari pergaulan dimana mereka tinggal, membina ibu-ibu agar hidup sehat, bersih di dalam rumah di lingkungannya serta menerapkan pengajaran-pengajaran bagaimana berperilaku yang baik terhadap orang lain, terutama dalam mendidik anakanaknya.

Kelompok pengajian dan Majelis ta'lim seminggu sekali diadakan pertemuan yang bertujuan lebih meningkatkan ketakwaan kepada tuhan serta lebih mempererat hubungan sesama kaum muslim. Begitu juga dengan kegiatan yang dilakukan oleh umat nasrani seperti kaum bapa dan kaum ibu melakukan ibadah bersama dan mendalami pemahaman alkitab.

Rasa kekeluargaan antara satu dengan yang lain begitu erat, dimana jika ada acara perkawinan mereka akan saling membantu yang biasa disebut gotong royong, untuk meringankan beban tuan pesta. Kerja sama atau gotong royong timbul apabila orang menyadari bahwa mereka mempunyai kepentingan-kepentingan yang sama dan pada saat yang sama mempunyai cukup pengendalian dan pengetahuan diri sendiri untuk memenuhi kepentingan-kepentingan tersebut melalui suatu kerja sama. Hal-hal seperti yang di atas dapat dilihat pada tabel di bawah ini. 
Tabel. Keadaan Karyawan PT. Delta Pasific Indotuna Menurut Organisai Sosial

\begin{tabular}{|c|l|c|}
\hline No & \multicolumn{1}{|c|}{ Kegiatan } & $\begin{array}{c}\text { Partisipasi } \\
\text { Perempuan }\end{array}$ \\
\hline 1 & Pesta & $* *$ \\
\hline 2 & $\begin{array}{l}\text { Majelis ta'lim/ibadah } \\
\text { kaum ibu }\end{array}$ & $*$ \\
\hline 3 & Kaum bapa & $* *$ \\
\hline 4 & Arisan & $*$ \\
\hline 5 & Kedukaan & $*$ \\
\hline 6 & Kerja bakti & - \\
\hline
\end{tabular}

Sumber : Data Primer diolah 2017

Keterangan: tanda (-) berarti tidak ada, $\left(^{*}\right)$ berarti ada, $\left({ }^{* *}\right)$ berarti banyak

Berdasarkan Tabel di atas menunjukkan bahwa, perempuan diranah sosial memiliki peran yang lebih dominan dibandingkan laki-laki. Persepsi masyarakat bahwa perempuan hanya berada diwilayah domestik saja, ini dapat diubah karena melihat bahwa andil perempuan cukup besar dalam hal kegiatan sosial seperti pesta, majelis ta'lim bagi perempuan yang beragama Islam, ibadah kaum ibu bagi perempuan yang beragama Kristen, dan arisan tetapi partisipasi perempuan dalam kegitan kedukaan dan kerja bakti yang ada di lingkungan tempat tinggal mereka tidak terlalu di dominasi oleh perempuan.

\section{Profil Akses Dan Kontrol}

Profil akses dan kontrol dilihat dari aspek sumberdaya dan manfaat. Aspek sumber daya terdiri atas sumber daya fisik atau material, dan pasar komoditas dan tenaga kerja. Sumber daya fisik atau material mencakup sarana produksi, dan bahan baku. Pasar komoditas dan tenaga kerja meliputi pembelian bahan baku, waktu dan tempat penjualan, jumlah yang akan dijual, harga jual, serta pengelolaan usaha.

Akses sumber daya fisik/ material paling banyak dilakukan oleh laki-laki dari keseluruhan aktivitas yang dinilai. Sedangkan, dalam akses dan kontrol pasar komoditas dan tenaga kerja dilakukan bersama antara laki-laki dan perempuan.

Kepemilikan hak pengambilan keputusan lebih banyak di miliki oleh laki-laki. Perempuan juga dapat memiliki hak pengambilan keputusan namun hak mereka tidak sebanyak laki-laki. Hal ini disebabkan karena sebagian besar pemegang hak pengambil keputusan di PT. Delta Pasifik Indotuna adalah lakilaki.

Tabel. Keadaan Karyawan Perempuan Menurut Akses dan Kontrol Atas Aset dan Sumberdaya

\begin{tabular}{|c|l|c|c|}
\hline No. & \multicolumn{1}{|c|}{ Kegiatan } & Akses & Kontrol \\
\hline 1 & Penetapan modal usaha & - & - \\
\hline 2 & Meminjam modal & - & - \\
\hline 3 & Penjualan hasil perikanan & $\sqrt{ }$ & $\sqrt{ }$ \\
\hline 4 & $\begin{array}{l}\text { Berapa banyak ikan yang } \\
\text { akan dijual }\end{array}$ & $\sqrt{ }$ & $\sqrt{ }$ \\
\hline 5 & Negosiasi harga ikan & - & - \\
\hline 6 & $\begin{array}{l}\text { Penggunaan } \\
\text { hasil/pendapatan }\end{array}$ & $\sqrt{ }$ & $\sqrt{ }$ \\
\hline 7 & $\begin{array}{l}\text { Memasarkan hasil } \\
\text { perikanan }\end{array}$ & $\sqrt{ }$ & $\sqrt{ }$ \\
\hline 8 & Mengetahui kualitas ikan & $\sqrt{ }$ & $\sqrt{ }$ \\
\hline
\end{tabular}

Sumber : Data Primer diolah 2017

Dalam akses Penetapan modal usaha, Meminjam modal, dan Negoisasi harga ikan laki-laki memegang hak penuh karena laki-laki dinilai lebih memiliki pengetahuan dalam bidang 
bahan baku dan sarana produksi. Selanjutnya dalam akses pasar komoditas dan tenaga kerja perempuan dan laki-laki dianggap memiliki kemampuan dan pengetahuan yang sama, sehingga akses dan kontrol pasar komoditas dan tenaga kerja memberikan hak yang sama dalam pengambilan keputusan.

\section{Faktor Yang Mempengaruhi Peran Perempuan}

Hasil penelitian ini menunjukkan bahwa perempuan memiliki tingkat beban kerja yang lebih tinggi dalam bidang produksi. Sedangkan dalam akses dan kontrol laki-laki memegang tingkat beban kerja yang lebih tinggi. Hal itu dipengaruhi oleh beberapa faktor seperti kemampuan kerja dan pengetahuan. Faktor kemampuan kerja dilihat dari banyaknya perempuan yang di tempatkan dalam bidang produksi. Faktor pengetahuan dilihat dari sebagian besarnya pemegang hak pengambil keputusan adalah laki-laki.

Faktor lain yang berpengaruh terhadap peran perempuan di PT. Delta Pasifik Indotuna adalah pendidikan. Kuatnya pengaruh pendidikan sangat terasa, hal ini dapat dilihat dari banyaknya quality control dan supervisor yang rata-rata adalah lulusan S1. Selain itu faktor umur dan tanggungan keluarga juga sangat berpengaruh terhadapa peran perempuan. Umur sangat mempengaruhi produktivitas seseorang sehingga sangat bepengaruh dalam peranannya dalam kegiatan produksi. Tanggungan keluarga adalah salah satu motivasi bagi karyawan agar dapat bekerja lebih aktif lagi, semakin banyak tanggungan keluarganya maka semakin tinggi pula semangat bekerjanya.

\section{Peran Perempuan Dalam Rantai Nilai Produksi Ikan Kaleng}

Perempuan merupakan salah satu komponen yang sangat penting dalam pembangunan kegiatan berbasis perikanan dan kelautan sebagai pedagang pengecer, pedagang perantara, pedagang besar, buruh upahan, maupun tenaga pengolah hasil perikanan. Peranan perempuan pedagang ikan pada rantai nilai pemasaran tuna cakalang dapat dilihat pada tabel di bawah ini.

Tabel. Peran Perempuan Dalam Rantai Nilai Produksi Ikan Kaleng di PT. Delta Pasific Indotuna

\begin{tabular}{|c|c|c|c|}
\hline No. & Aktivitas & $\begin{array}{c}\text { Jumlah } \\
\text { (Karyawan) }\end{array}$ & $\%$ \\
\hline 1 & Pemasakan awal & 1 & $1,12 \%$ \\
\hline 2 & Coolling & 2 & $2,25 \%$ \\
\hline 3 & $\begin{array}{l}\text { Beheading, } \\
\text { Skinning, Loinning }\end{array}$ & 40 & $44,94 \%$ \\
\hline 4 & $\begin{array}{l}\text { Pencucian Kaleng } \\
\text { Kosong }\end{array}$ & 10 & $11,24 \%$ \\
\hline 5 & $\begin{array}{l}\text { Packing, } \\
\text { penimbangan, } \\
\text { Filling Medium }\end{array}$ & 10 & $11,24 \%$ \\
\hline 6 & $\begin{array}{l}\text { Seaming, can } \\
\text { washing }\end{array}$ & 5 & $5,62 \%$ \\
\hline 7 & Pendinginan Kaleng & 3 & $3,37 \%$ \\
\hline 8 & Pengartonan & 8 & $8,99 \%$ \\
\hline 9 & Pelabelan & 10 & $11,24 \%$ \\
\hline & Jumlah & 89 & $100 \%$ \\
\hline
\end{tabular}

Sumber : Data Primer diolah 2017 
Hasil penelitian terkait peranan perempuan dalam rantai nilai ikan kaleng di PT. Delta Pasific Indotuna pada tabel di atas memberikan informasi bahwa peranan terbesar perempuan terdapat pada kegiatan Beheading, Skinning dan Loinning dengan presentase 44,94\%. Alasannya karena pada ketiga kegiatan ini sangat dituntut ketelitian tinggi yang sulit untuk dilakukan oleh laki-laki. Peran perempuan yang paling sedikit terdapat pada kegiatan cooling, kagiatan ini dinilai sulit untuk dilakukan oleh perempuan karena resiko dari pekerjaanya yang cukup tinggi.

\section{KESIMPULAN DAN SARAN}

\section{Kesimpulan}

Berdasarkan hasil dan pembahasan diperoleh beberapa kesimpulan berikut :

1. Perempuan di PT. Delta Pasific Indotuna tidak hanya berperan sebagai karyawan perusahaan biasa, namun juga berperan sebagai pimpinan departemen ataupun supervisor di perusahaan.

2. Perempuan sangat berperan penting dalam kegiatan Beheading, Skinning dan Loinning di PT. Delta Pasifik Indotuna dengan persentase $44,94 \%$ di bandingkan dengan kegiatan lainnya. Dengan banyaknya karyawan perempuan di bagian produksi maka membuktikan bahwa peran yang paling mempengaruhi dalam kegiatannya adalah perempuan.

\section{Saran}

1. Adanya kesetaraan hak pengambilan keputusan bagi karyawan perempuan yang bekerja di PT. Delta Pasifik Indotuna.

2. Melihat hasil karakteristik PT. Delta Pasifik Indotuna dapat ditinjau kembali kebijakan perusahaan terutama mengenai waktu kerja.

3.

\section{DAFTAR PUSTAKA}

Bungin, B. 2003. Analisis Data Penelitian Kuanlitatif. Penerbit PT. Raja Grafindo Persada, Jakarta.

Dinas Pertanian dan Perikanan Provinsi Sulawesi Utara. 2009. Laporan Tahunan Dinas Pertanian dan Perikanan Provinsi Sulawesi Utara.

Faisal, A. 2003. Dasar-Dasar Manajemen Keuangan. Malang : UMM Press.

Hamidi. 2010. Metode Penelitian Kualitatif. Sosial dan Populer. Gramedia Pustaka Jaya. Jakarta

Nazir, M. 2009. Metode Penelitian. Ghalia Indonesia. Jakarta.

Suyanto, B. dan Hendarso. 1996. Perempuan: Dari Subordinasi dan Marginalisasi Menuju ke Pemberdayaan.Airlangga University Press. Surabaya. 
